\title{
Experimental auction confirmation that social desirability bias does not predict willingness to pay for eco-labeled goods
}

\author{
Kieran Higgins * (D), Alberto Longo (D) and George Hutchinson \\ Gibson Institute for Land, Food \& Environment, School of Biological Sciences, Queen's University Belfast, Belfast, United \\ Kingdom \\ *Corresponding author. E-mail: k.higgins@qub.ac.uk
}

(Received 09 August 2021; Revised 25 September 2021; Accepted 06 October 2021)

\begin{abstract}
It is often assumed that consumers' willingness to pay (WTP) for eco-labeled products in research settings is not because of a desire for environmental protection, but rather that they are socially compelled to make decisions that reflects favorably on them, limiting the validity of findings. Using a second-price Vickrey experimental auction, this study found higher WTP for an eco-labeled product than a comparable good, but that social desirability bias, measured by the Marlowe-Crowne Social Desirability Scale, was not a significant predictor of WTP. Instead, environmental consciousness, environmental knowledge, education, and available information were stronger predictors of WTP for eco-labeled goods.
\end{abstract}

Key words: eco-label; experimental auction; second-price Vickrey auction; social desirability bias; willingness to pay

\section{Introduction}

Consumers are increasingly demanding sustainability in the goods they purchase, and the production and retailing industries are responding to this demand. Eco-labels, which refer to some form of distinct identifying mark, are used to provide information to the consumer about the sustainability of the product and allow for products to be differentiated in the marketplace (Gutierrez et al., 2020).

Willingness to pay (WTP) is defined as the maximum amount of money someone would be willing to part with to obtain a welfare improvement, here understood to be the environmental benefits associated with the eco-label. It serves as a common measure of demand and pricing for eco-labeled products. In general, WTP for eco-labeled goods is thought to be higher than nonlabeled goods because of this increase in environmental benefits (Lim \& Reed, 2020). This price premium provides an important incentive for producers and retailers to engage with eco-labeling schemes, as it offers the potential for price premia to offset the costs of more sustainable production (Blomquist et al., 2015) and to access to new markets, niche markets, or even markets perceived as "luxury" (Fuerst \& Shimizu, 2016).

There are numerous consumer characteristics which are believed to underpin the price premium and WTP for eco-labeled products that consumers have, and these provide important reference points for segmenting the market. These include gender, age, income, education, and many more (Higgins et al., 2020). Of course, the key predictor of WTP for an eco-labeled good should be the strength of the purchasers' desire to protect the environment. However, other factors may be at play.

\footnotetext{
(๑) The Author(s), 2021. Published by Cambridge University Press. This is an Open Access article, distributed under the terms of the Creative Commons Attribution licence (http://creativecommons.org/licenses/by/4.0), which permits unrestricted re-use, distribution and reproduction, provided the original article is properly cited.
} 
As a form of response bias, social desirability bias refers to the tendency of research subjects to provide responses (in this case, WTP for eco-labeled goods) that are not representative of their actual opinions or behaviors in the "real world," but more akin to answers deemed appropriate by their social reference group (Beretvas et al., 2002). Underlying this is a desire to look more attractive or superior to others (impression management) or to deceive themselves that they are "better" than they actually are (Larson, 2019).

As pro-environmental behavior increases and is seen as a social norm (Shafiei \& Maleksaeidi, 2020), it holds that people would like to portray themselves as eco-friendlier. If a customer feels compelled to purchase an expensive eco-labeled product in a public marketplace, for fear of exposing oneself as operating contrary to established norms, that represents a negative outcome for the consumer, who may not truly desire the product (at its current price), but it still continues to benefit the producer and the wider environment.

It is known that there is an "attitude-behavior" gap, particularly in the purchasing of green products, whereby customers may hold environmental attitudes but not demonstrating them in their choice of goods (Dhir et al., 2021) If such a gap persists between what a potential customer indicates in a research setting and their actual behavior in the marketplace, then producers and the environment both face detriment. Thus, determining this relationship is key to ensuring the continued uptake and success of eco-labeling schemes.

It follows that in studies of eco-labeled product choice and WTP for these products that social desirability may play a role-as a noted factor in marketing research generally (Larson, 2019) and directly influencing responses to eco-labeled products by producing over-reported or inflated estimates (Brécard et al., 2009; Cerri et al., 2019a).

A wide body of research has identified this relationship between social desirability bias and increasing WTP (Wheeler et al., 2019). However, there have been studies which have distinctly found the opposite, using both correlational and experimental investigation.

Gallardo and Wang (2013) found no such relationship between social desirability bias and WTP for eco-labeled fruit. Their method employed direct and indirect questioning techniques, which have been known to show a difference in attitudes to eco-friendly products, which is often attributed to social desirability bias (Klaiman et al., 2016).

Sörqvist, Haga, and their collaborators also found no such relationship between social desirability bias and WTP for eco-labeled goods such as light bulbs (Sörqvist et al., 2015a), bananas (Sörqvist et al., 2015b), and raisins (Sörqvist et al., 2016b), culminating in robust evidence that social desirability bias and WTP for eco-labeled goods had nothing to do with one another (Sörqvist et al., 2016a).

Despite this supposed confirmation, social desirability bias is still a concern for researchers in this area (Cai et al., 2017; Harms \& Linton, 2016; Slapø \& Karevold, 2019; Taufique et al., 2017; Testa et al., 2015), and is still being offered as an explanation for results (Barker et al., 2019; Vecchio et al., 2017) or acknowledged as a limitation for studies of WTP for eco-labeled products (Sogari et al., 2016; Vecchio \& Annunziata, 2015).

Here, a quantitative approach is proposed, with the introduction of a measured variable for the social desirability bias of individual participants, which would allow for it to be properly observed and controlled for (Ventimiglia \& MacDonald, 2012). This is common in other fields such as health (Bidaki et al., 2018; King et al., 2018), personality studies (Fernandez et al., 2018), and research into illegal or undesirable behavior (McClanahan et al., 2019), arguably situations in which people would be most likely to mispresent themselves, but is rarely implemented as a research technique in these types of valuation studies (Cerri et al., 2019b). Sörqvist et al. (2016b) are one of the few examples of this method being directly applied to WTP for eco-labeled products. In conjunction with an incentive-compatible, demand-revealing experiment, such as a Vickrey auction (Vickrey, 1961), it would clearly determine if high WTP values are directly a result of social desirability bias.

Therefore, the aim of this study is to determine if social desirability bias predicts a consumer's WTP for eco-labeled goods. This was achieved through an experimental auction approach, using a selfselection sample of Northern Irish adult consumers. To the best of the authors' knowledge, this is one 
of only a few papers to directly address this issue in WTP for eco-labeled goods, and the first does so in the context of an incentive compatible experimental auction.

This paper commenced with a discussion of the relevant background to the relationship between social desirability and eco-labels. Next, the methods used are presented, followed by the results and a discussion of the significance of these findings. The paper concludes with a discussion of the limitations of the study and suggests opportunities for future research.

\section{Materials and methods}

\subsection{Participants}

The target population was identified as a "Northern Irish consumer," proposed to be a Northern Ireland resident of any gender aged between 18 and 65. Following ethical approval, participants were recruited from among staff and students of Queen's University Belfast, using primarily volunteer self-selection and snowball sampling methods (Sharma, 2017). The final sample size was 92, and, as reported in Table 1, was fairly evenly balanced for gender, with most participants aged 18-24 (68.5\%), largely educated to undergraduate level (44.6\%), and mostly had an annual household income less than $£ 20,000(62 \%)$.

\subsection{Design and Procedure}

Recruited participants were assigned to cohorts of 20 and cross-matched for age and gender where possible. There were eight 1-hr-long laboratory sessions in total (expected sample size of 160), but with 25-50\% no-shows in most cohorts, the realized sample size was 92.

The experiment constituted a second-price, sealed-bid Vickrey laboratory auction. Here, the highest bidder wins the auction, but pays the runner-up's bid as their final price. Therefore, as the winner cannot influence the outcome of the auction by overbidding or underbidding, they are incentivized to bid only their true WTP (Milgrom, 2021). Participants were further incentivized to bid their exact WTP by being informed that the auction winner would also have the value of the winning bid deducted from their participation fee of $£ 20$.

After having the rules of the auction explained to them, participants were simultaneously shown the test goods: two wooden kitchen spoons, one of which was eco-labeled and the other not. Both goods were identical in physical characteristics. Participants were invited to examine the goods, and then, depending on the cohort, exposed to one of two information treatments. Well-informed participants (62\% of sample) were told that eco-labeled good was "made from wood from FSC-certified forests. This means that the forest it came from was managed in such a way to prevent negative impacts on local wildlife, water bodies, and air quality," while uninformed participants (38\% of sample) were only told that the ecolabeled good was "environmentally friendly and came from a sustainable forest."

Following this, the auction began, administered via computers using the $\mathrm{z}$-Tree software for economic experiments (Fischbacher, 2007). Bids for both goods were entered simultaneously, and this was repeated three times. As previously explained to participants, at the conclusion, one good and one of the three bids for it would be chosen at random as final and binding, further increasing the incentive compatibility of the experiment. Please consult Higgins et al. (2020) for a further description of the auction experiment method.

\subsection{Measures}

Following completion of the bidding, but before the results of the auction were revealed, participants completed a short onscreen questionnaire. They were first asked to provide details of their gender, income, age, education, and membership of an environmental organization. They were then asked to selfrate their environmental knowledge as either "I know a lot about environmental issues," "I know a little about environmental issues," or "I do not know anything about environmental issues." 
Table 1. Variables of interest and sample characteristics

\begin{tabular}{|c|c|c|}
\hline Variable & Categories & Percent \\
\hline \multirow[t]{2}{*}{ INFO $^{a}$} & Uninformed & 38.0 \\
\hline & Well-informed $^{\mathrm{b}}$ & 62.0 \\
\hline \multirow[t]{2}{*}{ GENDER } & Female & 53.3 \\
\hline & Male & 46.7 \\
\hline \multirow[t]{2}{*}{ AGE } & $18-24$ & 68.5 \\
\hline & 25 or older & 31.5 \\
\hline \multirow[t]{3}{*}{ HOUSEHOLD INCOME } & $£ 0-£ 19,000$ & 62.0 \\
\hline & $£ 20,000-£ 39,999$ & 28.3 \\
\hline & $£ 40,000+$ & 9.8 \\
\hline \multirow[t]{3}{*}{ EDUCATION } & GCSES or A levels & 22.8 \\
\hline & Undergraduate degree & 44.6 \\
\hline & Postgraduate or doctoral degree & 32.6 \\
\hline \multirow[t]{2}{*}{ ENVORG $^{c}$} & Nonmember & 81.5 \\
\hline & Member & 18.5 \\
\hline \multirow[t]{2}{*}{ ENVKNOW $^{\mathrm{d}}$} & Low-medium & 54.3 \\
\hline & High & 45.7 \\
\hline \multirow[t]{4}{*}{$\mathrm{NEP}^{\mathrm{e}}$} & Low & 26.1 \\
\hline & Medium & 47.8 \\
\hline & High & 26.1 \\
\hline & & Mean | SD \\
\hline \multirow[t]{2}{*}{ MCSCORE $^{f}$} & & $16.7 \mid 5.5$ \\
\hline & & $N=92$ \\
\hline
\end{tabular}

${ }^{\mathrm{a}}$ Treatment for information effects.

${ }^{b}$ See methods for a description of these treatments.

${ }^{\mathrm{c} M e m b e r s h i p ~ o f ~ a n ~ e n v i r o n m e n t a l ~ o r g a n i z a t i o n . ~}$

${ }^{\mathrm{d}}$ Self-rated knowledge of environmental issues.

eNew Ecological Paradigm score.

${ }^{f}$ Marlowe-Crowne Social Desirability Bias score.

Next, participants were asked to measure their environmental consciousness using the Revised New Ecological Paradigm (NEP), a 15-statement scale answered on a 7-point Likert scale from strongly agree to strongly disagree (Dunlap et al., 2000). This generates final scores out of 105 for each participant, which are divided into three quartiles. Those scoring in the upper quartile are coded as high, middle quartile as medium, and lower quartile as low in respect to their environmental consciousness.

Finally, the participant's vulnerability to social desirability biased was measured using the MarloweCrowne Social Desirability Scale (MCSCORE; Crowne \& Marlowe, 1960). The participant answers 33 true or false questions (as described in Table 2), receiving a point for each response that is considered socially desirable. The higher this score, the more likely social desirability bias is occurring in that participant's thoughts and behavior. Typically, the shorter forms of this scale are used (Sörqvist et al., 2015b), but the long form was used here with the intention of increasing validity and reliability of the scale.

The auction concluded with the private reveal of the winner, who received their randomly chosen good, and the final payment of the fee to participants, minus their randomly chosen bid in the case of the auction winner. 
Table 2. Marlowe-Crowne Social Desirability Scale

1. Before voting I thoroughly investigate the qualifications of all the candidates.

2. I never hesitate to go out of my way to help someone in trouble.

3. It is sometimes hard for me to go on with my work if I am not encouraged.

4. I have never intensely disliked anyone.

5. On occasions I have had doubts about my ability to succeed in life.

6 . I sometimes feel resentful when I do not get my way.

7. I am always careful about my manner of dress.

8. My table manners at home are as good as when I eat out in a restaurant.

9. If I could get into a movie without paying and be sure I was not seen, I would probably do it.

10. On a few occasions, I have given up something because I thought too little of my ability.

11. I like to gossip at times.

12. There have been times when I felt like rebelling against people in authority even though I knew they were right.

13. No matter who I'm talking to, I'm always a good listener.

14. I can remember "playing sick" to get out of something.

15. There have been occasions when I have taken advantage of someone.

16. I'm always willing to admit it when I make a mistake.

17. I always try to practice what I preach.

18. I do not find it particularly difficult to get along with loud mouthed, obnoxious people.

19. I sometimes try to get even rather than forgive and forget.

20. When I do not know something I do not mind at all admitting it.

21. I am always courteous, even to people who are disagreeable.

22. At times I have really insisted on having things my own way.

23. There have been occasions when I felt like smashing things.

24. I would never think of letting someone else be punished for my wrong-doings.

25. I never resent being asked to return a favor.

26. I have never been irked when people expressed ideas very different from my own.

27. I never make a long trip without checking the safety of my car.

28. There have been times when I was quite jealous of the good fortune of others.

29. I have almost never felt the urge to tell someone off.

30. I am sometimes irritated by people who ask favors of me.

31. I have never felt that I was punished without cause.

32. I sometimes think when people have a misfortune they only got what they deserved.

33. I have never deliberately said something that hurt someone's feelings.

\section{Results}

The data from all 92 participants were retained for analysis. The characteristics of this sample are reported in the Methods section and in Table 1. The participants were mostly nonmembers of environmental organizations (81.5\%), with low-to-medium environmental knowledge (54.3\%) and a medium level of environmental consciousness $(47.8 \%)$. The participants had a moderate level of social 
desirability bias $(M=16.7, S D=5.5)$, with 6 participants having a low level, 57 having a medium level, and 29 having a high level.

Combining the bids for all three rounds for both goods showed a higher mean bid for the eco-labeled

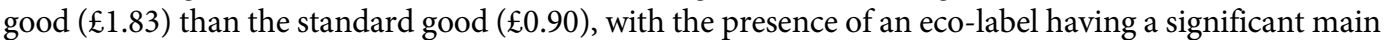
effect on the bid offered $(F(1,550)=111.61, p<.001)$. When social desirability was incorporated into the model, the eco-label continued to have significant main effect $(F(1,549)=111.41, p<.001)$, but there was no effect of social desirability on the bid offered $(F(1,549)=0.01, p=.94)$.

The results of the regression models are reported in Table 3. Using only the bids for the eco-labeled good, a Tobit model was estimated to explore the relationship between WTP and proneness to social desirability bias as measured by the MCSCORE. MCSCORE was not a significant predictor $(\beta=-0.006)$

Table 3. Tobit model results

\begin{tabular}{|c|c|c|c|c|}
\hline \multicolumn{5}{|c|}{ Dependent variable: bids offered for sustainable good $(\mathfrak{E})$} \\
\hline & Model I & Model II & Model III & Model IV \\
\hline \multirow[t]{2}{*}{ INTERCEPT } & $1.900^{* * *}$ & $2.900^{* * *}$ & $2.900^{* * *}$ & $1.200^{\text {***}}$ \\
\hline & $(0.230)$ & $(0.720)$ & $(0.720)$ & $(0.220)$ \\
\hline \multirow[t]{2}{*}{ MCSCORE } & -0.006 & -0.012 & -0.012 & \\
\hline & $(0.013)$ & $(0.013)$ & $(0.013)$ & \\
\hline INFO & & $-0.320^{* *}$ & $-0.290^{* *}$ & $-0.290^{\star \star}$ \\
\hline (ref $=$ uninformed $)$ & & $(0.150)$ & $(0.150)$ & $(0.150)$ \\
\hline GENDER: male & & -0.021 & & \\
\hline (ref $=$ female) & & $(0.150)$ & & \\
\hline AGE: 25 and above & & 0.190 & & \\
\hline$(r e f=18-24)$ & & $(0.190)$ & & \\
\hline HOUSEHOLD INCOME: $£ 20,000-£ 39,000$ & & 0.048 & & \\
\hline$($ ref $=<£ 19,000)$ & & $(0.170)$ & & \\
\hline HOUSEHOLD INCOME: $£ 40,000+$ & & -0.230 & & \\
\hline$($ ref $=<£ 19,000)$ & & $(0.230)$ & & \\
\hline EDUCATION: undergraduate & & $0.430^{\star *}$ & $0.430^{\star *}$ & $0.440^{\star *}$ \\
\hline (ref $=$ GCSEs or $A$ levels) & & $(0.180)$ & $(0.180)$ & $(0.180)$ \\
\hline EDUCATION: postgraduate & & $0.570^{* *}$ & $0.650^{\star \star *}$ & $0.640^{* * *}$ \\
\hline (ref $=$ GCSEs or A levels) & & $(0.220)$ & $(0.190)$ & $(0.190)$ \\
\hline ENVORG: member & & -0.083 & & \\
\hline (ref $=$ nonmember) & & $(0.200)$ & & \\
\hline ENVKNOW: high & & $0.260^{*}$ & $0.260^{*}$ & $0.270^{\star *}$ \\
\hline$($ ref $=$ low-medium $)$ & & $(0.150)$ & $(0.140)$ & $(0.140)$ \\
\hline NEP: medium & & $0.620^{* * *}$ & $0.630^{* * *}$ & $0.610^{* * *}$ \\
\hline$($ ref $=$ low $)$ & & $(0.200)$ & $(0.190)$ & $(0.190)$ \\
\hline NEP: high & & 0.290 & $0.310^{*}$ & $0.320^{*}$ \\
\hline$($ ref $=$ low $)$ & & $(0.180)$ & $(0.170)$ & $(0.170)$ \\
\hline
\end{tabular}


Table 3. Continued

\begin{tabular}{|c|c|c|c|c|}
\hline \multicolumn{5}{|c|}{ Dependent variable: bids offered for sustainable good $(\mathfrak{E})$} \\
\hline & Model I & Model II & Model III & Model IV \\
\hline Observations & 276 & 276 & 276 & 276 \\
\hline Log likelihood & -438.000 & -420.000 & -421.000 & -422.000 \\
\hline AIC & $881(d f=1)$ & $874(d f=12)$ & $866(d f=7)$ & $\begin{array}{l}865 \\
(d f=6)\end{array}$ \\
\hline Wald test & $\begin{array}{l}0.240^{* * *} \\
(d f=1)\end{array}$ & $\begin{array}{c}37.000^{* * *} \\
(d f=12)\end{array}$ & $\begin{array}{r}35.000^{* * *} \\
(d f=7)\end{array}$ & $\begin{array}{r}34.000^{* * *} \\
(d f=6)\end{array}$ \\
\hline
\end{tabular}

${ }^{*} p<.1$.

$* \star x<.05$

${ }^{\star \star \star} p<.01$.

of WTP. The model was re-estimated using all predictor variables measured (Model II) and then with only the significant predictor variables (Model III). Across all three models, MCSCORE was a weak predictor and not significant. It was then dropped from the model (Model IV), and the Akaike Information Criterion score improved, indicating a better goodness of fit without the MCSCORE variable. The final model instead included the information treatment, and the education, environmental knowledge, and environmental consciousness of the participants.

\section{Conclusions}

The aim of this study was to determine if social desirability bias is a significant predictor of WTP for ecolabeled goods. To the best of the authors' knowledge, it is only one of a few studies to address this relationship, and the first to provide confirmation through the use of an experimental auction approach, combined with the use of the full MCSCORE.

The results of this study show that, although people are willing to pay more for eco-labeled products, social desirability bias is a poor predictor of WTP for eco-labeled goods. In line with previous studies, social desirability bias does not seem to influence WTP for eco-labeled goods (Gallardo \& Wang, 2013; Sörqvist et al., 2015a; 2015b; 2016a; 2016b). Instead, other factors emerge as much stronger predictors of WTP, including information provided by the label, and the levels of education, environmental knowledge, and environmental consciousness of the participants. Specifically, the last factor indicates that participants are indeed reflecting their concern for the environment in their choice and valuation of environmentally friendly goods.

Therefore, it would hold that the traditional theory about eco-labels is true: purchase behavior is positively and significantly related to internal desires to protect the environment, rather than any desire to deceive oneself or the experimenter based on the affirming social reference group. It could be argued then, that pro-environmental behavior, such as choosing eco-labeled goods, has moved from a perceived, injunctive, or subjective norm that is largely socially performative, to a collective or descriptive norm, that it is simply what is now done (Chung \& Rimal, 2016).

An alternative explanation is that the auction experiment used here is entirely incentive-compatible and demand-revealing (Noussair et al., 2004), and that the participants had no choice but to reveal their exact WTP, free from social desirability bias. Social desirability bias is based on the theory that there are risks to answering truthfully but very few rewards for doing so (Cerri et al., 2019a), but here, the participant anonymity, lack of outcome control, and the participant's risk of losing a real-world financial endowment by bidding in a socially desirable way may have overridden this impulse to answer in a biased manner. 
For researchers, these results may suggest that, while it is good practice to attempt to test and control for it, incentive compatible WTP studies, for eco-labeled products at least, are somewhat free from social desirability bias. Researchers can test and be assured of this by incorporating a measure of social desirability bias such as the MCSCORE.

For marketers, the findings may suggest that marketing campaigns relying on the influence of social norms to encourage purchase of eco-labeled or other green goods are perhaps not as efficient as previously thought and should instead focus on activating the environmental concern possessed by the potential customer, perhaps through information campaigns and the design of the product information and the label itself.

The authors propose the following limitations to the study. First, the sample size is rather small, but small samples are common in experimental research such as this and should be sufficient for a confirmatory study. The sample itself approximates a volunteer, self-selection sample made up mostly of students, but if anything, these are the people considered most likely to display social desirability bias (Hood \& Back, 1971), lending weight to the theory that social desirability bias does not predict WTP for eco-labeled goods, even among this group of subjects.

Second, the findings for this good (wooden kitchen spoon) may not generalize to other goods. These particular goods were chosen as participants would have a high degree of familiarity with them, given that low product involvement (familiarity with use, attributes, and alternatives) can create inaccuracies in valuation (Park \& Keil, 2019). However, these simple goods do provide a strong, bias-free foundation for valuation work.

Third, the use of the MCSCORE may not have been appropriate, due to either an overall lack of validity, or decreased validity in this particular application (Uziel, 2010). It may not truly capture the selfdeception aspect of social desirability bias (Leite \& Beretvas, 2005). Crowne, one of the creators of the scale, was himself critical of its deployment as a control mechanism in experimental research and stated that any belief that it can decontaminate the research or its variables is flawed (Crowne, 1991). While concerns about the reliability and validity of this scale persists, particularly among male participants (Beretvas et al., 2002), it still consistently outperforms other scales in detecting social desirability bias (Vésteinsdóttir et al., 2017).

Future research could repeat similar experiments, perhaps using a larger probability-based sample, for a wider range of eco-labeled goods with different eco-labeled types and using alternative scales of social desirability bias that are available (Uziel, 2010).

Acknowledgment. The authors would like to thank the NI Department of Agriculture, Environmental and Rural Affairs for supporting the research through their generous Postgraduate Studentships.

Conflicts of interest. The authors have no conflicts of interest to disclose.

Authorship contributions. K.H. conceived and designed the study and carried out data analysis and data collection. A.L. and G.H. contributed to the experimental design and advised on the analysis. All authors contributed equally to the writing of the article.

Data availability statement. Please contact the corresponding author to access this dataset.

\section{References}

Barker, M. E., Wong, F., Jones, C. R., \& Russell, J. M. (2019). Food purchasing decisions and environmental ideology: An exploratory survey of UK shoppers. Sustainability, 11, 6279. https://doi.org/10.3390/su11226279

Beretvas, S. N., Meyers, J. L., \& Leite, W. L. (2002). A reliability generalization study of the Marlowe-Crowne Social Desirability Scale. Educational and Psychological Measurement, 62, 570-589. https://doi.org/10.1177/0013164402062004003

Bidaki, R., Majidi, N., Ahmadi, A. M., Bakhshi, H., Mohammadi, R. S., Mostafavi, S. A., Arababadi, M. K., Hadavi, M., \& Mirzaei, A. (2018). Vitiligo and social acceptance. Clinical, Cosmetic and Investigational Dermatology, 11, 383-386. https:// dx.doi.org/10.2147\%2FCCID.S151114

Blomquist, J., Bartolino, V., \& Waldo, S. (2015). Price premiums for providing eco-labelled seafood: Evidence from MSCcertified cod in Sweden. Journal of Agricultural Economics, 66, 690-704. https://doi.org/10.1111/1477-9552.12106 
Brécard, D., Hlaimi, B., Lucas, S., Perraudeau, Y., \& Salladarré, F. (2009). Determinants of demand for green products: An application to eco-label demand for fish in Europe. Ecological Economics, 69, 115-125. https://doi.org/10.1016/j. ecolecon.2009.07.017

Cai, Z., Xie, Y., \& Aguilar, F. X. (2017). Eco-label credibility and retailer effects on green product purchasing intentions. Forest Policy and Economics, 80, 200-208. https://doi.org/10.1016/j.forpol.2017.04.001

Cerri, J., Testa, F., Rizzi, F., \& Frey, M. (2019a). Factorial surveys reveal social desirability bias over self-reported organic fruit consumption. British Food Journal, 121, 897-909. https://doi.org/10.1108/BFJ-04-2018-0238

Cerri, J., Thøgersen, J., \& Testa, F. (2019b). Social desirability and sustainable food research: A systematic literature review. Food Quality and Preference, 71, 136-140. https://doi.org/10.1016/j.foodqual.2018.06.013

Chung, A., \& Rimal, R. N. (2016). Social norms: A review. Review of Communication Research, 4, 1-29. https://doi.org/ 10.12840

Crowne, D. P. (1991). From response style to motive-A citation-classic commentary on The Approval Motive: Studies in Evaluative Dependence by Crowne, D. P. and Marlowe, D. Current Contents-Social \& Behavioral Sciences (Vol. 30, pp. 1-10).

Crowne, D. P., \& Marlowe, D. (1960). A new scale of social desirability independent of psychopathology. Journal of Consulting Psychology, 24, 349-354. https://doi.org/10.1037/h0047358

Dhir, A., Sadiq, M., Talwar, S., Sakashita, M., \& Kaur, P. (2021). Why do retail consumers buy green apparel? A knowledgeattitude-behaviour-context perspective. Journal of Retailing and Consumer Services, 59, 102398. https://doi.org/10.1016/ j.jretconser.2020.102398.

Dunlap, R. E., Van Liere, K. D., Mertig, A. G., \& Jones, R. E. (2000). Measuring endorsement of the New Ecological Paradigm: A revised NEP Scale. Journal of Social Issues, 56, 425-442. https://doi.org/10.1111/0022-4537.00176

Fernandez, E., Woldgabreal, Y., Guharajan, D., Day, A., Kiageri, V., \& Ramtahal, N. (2018). Social desirability bias against admitting anger: Bias in the test-taker or bias in the test?. Journal of Personality Assessment, 101, 644-652. https://doi.org/ 10.1080/00223891.2018.1464017

Fischbacher, U. (2007). z-Tree: Zurich toolbox for ready-made economic experiments. Experimental Economics, 10, 171-178. https://doi.org/10.1007/s10683-006-9159-4

Fuerst, F., \& Shimizu, C. (2016). Green luxury goods? The economics of eco-labels in the Japanese housing market. Journal of the Japanese and International Economies, 39, 108-122. https://doi.org/10.1016/j.jjie.2016.01.003

Gallardo, R. K., \& Wang, Q. (2013). Willingness to pay for pesticides' environmental features and social desirability bias: The case of apple and pear growers. Journal of Agricultural and Resource Economics, 38, 124-139. https://doi.org/10.22004/ ag.econ. 148250

Gutierrez, A. M. J., Chiu, A. S. F., \& Seva, R. (2020). A proposed framework on the affective design of eco-product labels. Sustainability, 12, 3234. https://doi.org/10.3390/su12083234

Harms, R., \& Linton, J. D. (2016). Willingness to pay for eco-certified refurbished products: The effects of environmental attitudes and knowledge. Journal of Industrial Ecology, 20, 893-904. https://doi.org/10.1111/jiec.12301

Higgins, K., Hutchinson, W. G., \& Longo, A. (2020). Willingness-to-pay for eco-labelled forest products in Northern Ireland: An experimental auction approach. Journal of Behavioral and Experimental Economics, 87, 87101572. https://doi.org/ 10.1016/j.socec.2020.101572

Hood, T. C., \& Back, K. W. (1971). Self-disclosure and the volunteer: A source of bias in laboratory experiments. Journal of Personality and Social Psychology, 17, 130. https://doi.org/10.1037/h0030380

King, B. M., Cespedes, V. M., Burden, G. K., Brady, S. K., Clement, L. R., Abbott, E. M., Baughman, K. S., Joyner, S. E., Clark, M. M., \& Pury, C. L. S. (2018). Extreme under-reporting of body weight by young adults with obesity: Relation to social desirability. Obesity Science \& Practice, 4, 129-133. https://doi.org/10.1002/osp4.153

Klaiman, K., Ortega, D. L., \& Garnache, C. (2016). Consumer preferences and demand for packaging material and recyclability. Resources, Conservation and Recycling, 115, 1-8. https://doi.org/10.1016/j.resconrec.2016.08.021

Larson, R. B. (2019). Controlling social desirability bias. International Journal of Market Research, 61, 534-547. https://doi.org/ $10.1177 / 1470785318805305$

Leite, W. L., \& Beretvas, S. N. (2005). Validation of scores on the Marlowe-Crowne Social Desirability Scale and the balanced inventory of desirable responding. Educational and Psychological Measurement, 65, 140-154. https://doi.org/10.1177\% 2F0013164404267285

Lim, K. H., \& Reed, M. (2020). Do ecolabels cheapen wines? Journal of Cleaner Production, 245, 118696. https://doi.org/ 10.1016/j.jclepro.2019.118696.

McClanahan, W., van der Linden, S., \& Ruggeri, K. (2019). Decision-making style mediates the relationship between trait selfcontrol and self-reported criminal behavior. Personality and Individual Differences, 151, 109537. https://doi.org/10.1016/ j.paid.2019.109537

Milgrom, P. (2021). Auction research evolving: Theorems and market designs. American Economic Review, 111, $1383-1405$. https://doi.org/10.1257/aer.111.5.1383 
Noussair, C., Robin, S., \& Ruffieux, B. (2004). Revealing consumers' willingness-to-pay: A comparison of the BDM mechanism and the Vickrey auction. Journal of Economic Psychology, 25, 725-741. https://doi.org/10.1016/j. joep.2003.06.004

Park, S. C., \& Keil, M. (2019). The moderating effects of product involvement on escalation behavior. Journal of Computer Information Systems, 59, 218-232. https://doi.org/10.1080/08874417.2017.1328648

Shafiei, A., \& Maleksaeidi, H. (2020). Pro-environmental behavior of university students: Application of protection motivation theory. Global Ecology and Conservation, 22, 00908. https://doi.org/10.1016/j.gecco.2020.e00908

Sharma, G. (2017). Pros and cons of different sampling techniques. International Journal of Applied Research, 3, 749-752.

Slapø, H. B., \& Karevold, K. I. (2019). Simple eco-labels to nudge customers toward the most environmentally friendly warm dishes: An empirical study in a cafeteria setting. Frontiers in Sustainable Food Systems, 3. https://doi.org/10.3389/ fsufs.2019.00040

Sogari, G., Mora, C., \& Menozzi, D. (2016). Sustainable wine labeling: A framework for definition and consumers' perception. Agriculture and Agricultural Science Procedia, 8, 58-64. https://doi.org/10.1016/j.aaspro.2016.02.008

Sörqvist, P., Haga, A., Holmgren, M., \& Hansla, A. (2015a). An eco-label effect in the built environment: Performance and comfort effects of labeling a light source environmentally friendly. Journal of Environmental Psychology, 42, 123-127. http:// dx.doi.org/10.1016/j.jenvp.2015.03.004

Sörqvist, P., Haga, A., Langeborg, L., Holmgren, M., Wallinder, M., Nöstl, A., Seager, P. B., \& Marsh, J. E. (2015b). The green halo: Mechanisms and limits of the eco-label effect. Food Quality and Preference, 43, 1-9. http://dx.doi.org/10.1016/ j.foodqual.2015.02.001

Sörqvist, P., Langeborg, L., \& Marsh, J. E. (2016a). Social desirability does not underpin the eco-label effect on product judgments. Food Quality and Preference, 50, 82-87. http://dx.doi.org/10.1016/j.foodqual.2016.01.010

Sörqvist, P., Marsh, J. E., Holmgren, M., Hulme, R., Haga, A., \& Seager, P. B. (2016b). Effects of labeling a product ecofriendly and genetically modified: A cross-cultural comparison for estimates of taste, willingness to pay and health consequences. Food Quality and Preference, 50, 65-70. http://dx.doi.org/10.1016/j.foodqual.2016.01.007

Taufique, K. M. R., Vocino, A., \& Polonsky, M. J. (2017). The influence of eco-label knowledge and trust on proenvironmental consumer behaviour in an emerging market. Journal of Strategic Marketing, 25, 511-529. https://doi.org/ 10.1080/0965254X.2016.1240219

Testa, F., Iraldo, F., Vaccari, A., \& Ferrari, E. (2015). Why eco-labels can be effective marketing tools: Evidence from a study on Italian consumers. Business Strategy and the Environment, 24, 252-265. https://doi.org/10.1002/bse.1821

Uziel, L. (2010). Rethinking social desirability scales: From impression management to interpersonally oriented self-control. Perspectives on Psychological Science, 5, 243-262. https://doi.org/10.1177\%2F1745691610369465

Vecchio, R., \& Annunziata, A. (2015). Willingness-to-pay for sustainability-labelled chocolate: An experimental auction approach. Journal of Cleaner Production, 86, 335-342. http://dx.doi.org/10.1016\%2Fj.jclepro.2014.08.006

Vecchio, R., Decordi, G., Grésillon, L., Gugenberger, C., Mahéo, M., \& Jourjon, F. (2017). European consumers' perception of moderate wine consumption on health. Wine Economics and Policy, 6, 14-22. https://doi.org/10.1016/j.wep.2017.04.001

Ventimiglia, M., \& MacDonald, D. A. (2012). An examination of the factorial dimensionality of the Marlowe Crowne Social Desirability Scale. Personality and Individual Differences, 52, 487-491. https://doi.org/10.1016/j.paid.2011.11.016

Vésteinsdóttir, V., Reips, U. D., Joinson, A., \& Thorsdottir, F. (2017). An item level evaluation of the Marlowe-Crowne Social Desirability Scale using item response theory on Icelandic Internet panel data and cognitive interviews. Personality and Individual Differences, 107, 164-173. https://doi.org/10.1016/j.paid.2016.11.023

Vickrey, W. (1961). Counterspeculation, auctions, and competitive sealed tenders. The Journal of Finance, 16, 8-37.

Wheeler, S. A., Gregg, D., \& Singh, M. (2019). Understanding the role of social desirability bias and environmental attitudes and behaviour on South Australians' stated purchase of organic foods. Food Quality and Preference, 74, 125-134. https:// doi.org/10.1016/j.foodqual.2019.01.007

Cite this article: Higgins K, Longo A, Hutchinson G (2022). Experimental auction confirmation that social desirability bias does not predict willingness to pay for eco-labeled goods. Experimental Results, 3, e1, 1-14. https://doi.org/10.1017/exp.2021.24 


\title{
Peer Reviews
}

\section{Reviewing editor: Dr. Jessica Payne}

University of Notre Dame, Notre Dame, Indiana, United States, 46556

This article has been accepted because it is deemed to be scientifically sound, has the correct controls, has appropriate methodology and is statistically valid, and has been sent for additional statistical evaluation and met required revisions.

\section{doi:10.1017/exp.2021.24.pr1}

\section{Review 1: Experimental auction confirmation that social desirability bias does not predict willingness-to-pay for eco-labelled goods}

\section{Reviewer: Dr. Riccardo Vecchio}

University of Naples Federico II, Agricultural Sciences, Via Università, 100, Portici, Napoli, Italy, 80055

Date of review: 03 September 2021

\begin{abstract}
(C) The Author(s), 2021. Published by Cambridge University Press. This is an Open Access article, distributed under the terms of the Creative Commons Attribution licence (http://creativecommons.org/licenses/by/4.0), which permits unrestricted re-use, distribution and reproduction, provided the original article is properly cited.
\end{abstract}

Conflict of interest statement. Reviewer declares none

\section{Comment}

Comments to the Author: The paper is well developed and offers important insights to scholars. I suggest to add some caveats related to the use of only one product type (wooden kitchen spoons). I also advice Authors to better clarify the number of participants in each experimental session (92:8?) and its length.

\section{Score Card}

\section{Presentation}

Does the paper cite relevant and related articles appropriately? (30\%)

\section{Context}

Does the title suitably represent the article? (25\%)

Does the abstract correctly embody the content of the article? (25\%)

Does the introduction give appropriate context? (25\%) 
Analysis

Is the conclusion consistent with the results and discussion? (40\%)

Are the limitations of the experiment as well as the contributions of the experiment clearly outlined? (20\%) 


\section{Review 2: Experimental auction confirmation that social desirability bias does not predict willingness-to-pay for eco-labelled goods}

Reviewer: Dr. Micheal Jay Polonsky

Deakin University Faculty of Business and Law, Department of Marketing, Burwood, Australia, 3125

Date of review: 10 September 2021

(C) The Author(s), 2021. Published by Cambridge University Press. This is an Open Access article, distributed under the terms of the Creative Commons Attribution licence (http://creativecommons.org/licenses/by/4.0), which permits unrestricted re-use, distribution and reproduction, provided the original article is properly cited.

Conflict of interest statement. NONE

\section{Comment}

Comments to the Author: The topic is of course interesting, as if there is a social desirability response this does not reflect actual intentions. They refer to this gap, which has been extensively studied in other environmental areas using the attitude behaviour gap, and this literature should at least be mentioned.

The authors might want to have a bit more discussion of the sealed-bid Vickrey laboratory auction and refer to literature that does say it reflects a truer price. While they might not be able to influence the price by overbidding, they also don't necessarily lose by overbidding. Thus, some additional discussion of the literature demonstrating people respond as suggested is valuable.

Did the authors assess the impact of the alternative messaging in regards to perceived level of greenness to ensure that the consumers in fact interpreted the two messages differently?

While regression models are fine for testing effects, other methods such as using PROCESS <https:// www.processmacro.org/index.html> allows for exploration of moderation and mediation effects and might provided more nuanced details rather than a Tobit model.

\section{Score Card}

Presentation

4.0

Is the article written in clear and proper English? (30\%)

Is the data presented in the most useful manner? (40\%)

Does the paper cite relevant and related articles appropriately? (30\%)

Context

Does the title suitably represent the article? (25\%)

Does the abstract correctly embody the content of the article? (25\%)

Does the introduction give appropriate context? (25\%)

Is the objective of the experiment clearly defined? (25\%) 
Analysis

Is the conclusion consistent with the results and discussion? (40\%)

Are the limitations of the experiment as well as the contributions of the experiment clearly outlined? (20\%) 